\title{
Ultrastructure of Odontoblasts in Dentinal Tubules of Mice
}

\author{
R. E. CORPRON and J. K. AVERY \\ Departments of Pedodontics and Oral Biology, School of Dentistry, The University of Mich- \\ igan, Ann Arbor, Michigan 48104, USA
}

The presence of odontoblasts in dentinal tubules has been noted by numerous investigators. One of the first to describe their presence was B. Orban ( $J$ Dent Res 20:553-557, 1941). The cells were in tubules associated with forceps marks on the root surfaces. Odontoblasts in dentinal tubules have been reported due to various types of trauma to pulps. Cavity preparation (V. E. JAMES and I. Schour, J Dent Res 34:698-699, 1955; LEFKOWITZ ET AL, Ohio State Dent Soc J 31:24-27, 1957; E. A. MARSLAND and D. S. ShOVELTON, Brit Dent J 102: 213-222, 1957; D. S. Shovelton and E. A. MARSLAND, Brit Dent $J$ 105:16-26, 1958; K. LANGEland, Odont $T$ 65:249-386, 1957; J. J. KenNedy ET AL, Dent Prog 3:10-16, 1962; M. Brannstrom, Odont Rev 14:224-253, 1963; and others) elicited this response when the cavities were cut dry or when severe trauma was provoked. Others such as I. R. H. Kramer and J. W. McLean (Brit Dent J 92:255-261, 1952), O. Muller and B. Maeglin (Int Dent J 4:167, 1953), and K. Langeland (Odont $T$ 68:463472,1960 ) found this response under various filling materials, especially in unlined cavities. H. R. Stanley and H. Swerdlow ( $J A D A$ 58: $49-59,1959)$ related the appearance of aspirated odontoblasts to the degree of inflammation.

Most investigators agree that this occurs soon after the toxic stimulus is applied, as noted in specimens collected 24 hours after treatment. M. B. Weiss, M. Massler, and J. M. Spence (Dent Prog 4:10-19, 1963) also found that extraction of teeth may cause this response. Thus squeezing of the pulp may force the odontoblasts into the dentinal tubules.

The present observations on the teeth of mature mice prepared for electron microscopy in a study of the normal development pattern of dentin included study of the ultrastructural appearance of odontoblasts in the tubules in some of the teeth that had been extracted with forceps. The teeth were fixed in $1.33 \%$ osmic acid in $s$-collidine buffer at $4 \mathrm{C}$ for two hours, dehydrated through graded alcohols and propylene oxide and embedded in Epon 812, sectioned at 500 to $800 \mathrm{~A}$, and viewed on an Hitachi 8 electron microscope. In Figure 1 an elongated odontoblast is seen in the upper left within a tubule located partly in the predentin (lower left) and partly in the more highly calcified dentin (upper right). This electron micrograph shows the presence of the organelles within the cell as well as the dark stained

This work was supported by USPHS Research Grant DE 01604 from the National Institute of Dental Research, National Institutes of Health, Bethesda, Md.

Additional information available on request to authors. Received for publication July 24, 1970.

J Dent Res March-April 1971, Vol 50 No. 2 nucleus. Figure 2 shows a cross section of dentin revealing odontoblast nuclei present in three dentinal tubules. The two upper tubules, and the one in the lower left, show the odontoblast nuclei in cross section almost completely filling the tubules. The lower right tubule shows part of the cytoplasm of the odontoblast rather than the nucleus. The surrounding dentinal matrix shows some calcified dentin as well as collagen fibers that are not calcified. Thus the odontoblasts are located within tubules of the predentin and adjacent dentin matrix. These inclusions appear in regions of the tooth adjacent to where the beaks of the forceps were placed in removal of the teeth. Since the teeth are small, it is probable that undue pressure was applied during the extraction procedures. These teeth received no other insult, such as cavity preparation, that could have accounted for this finding.

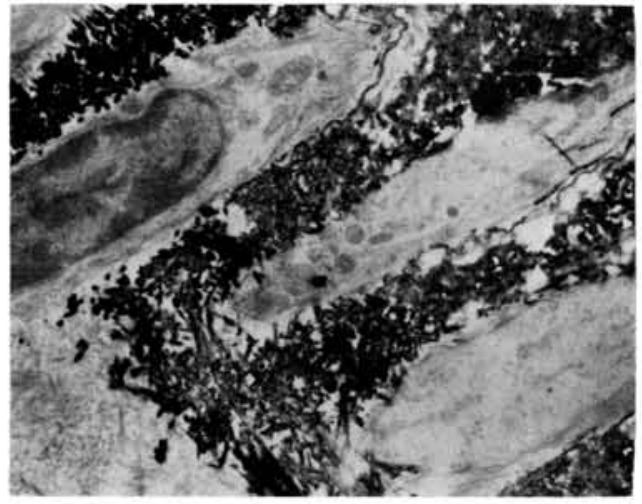

FIG 1.-Elongated odontoblast in dentinal tubule.

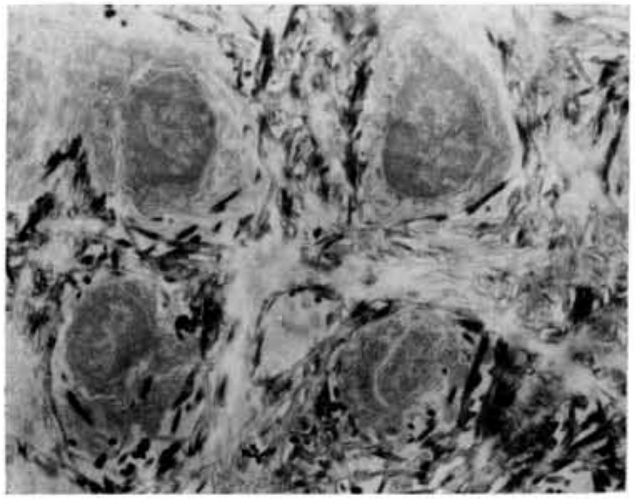

FIG 2.-Cross section of dentin shows odontoblast nuclei in dentinal tubules. 